\title{
The effect of short-course antibiotics on the resistance profile of colonizing gut bacteria in the ICU: a prospective cohort study
}

\author{
Christian Munck**, Ravi U. Sheth ${ }^{1}$, Edward Cuaresma ${ }^{2}$, Jessica Weidler ${ }^{3}$, Stephania L. Stump ${ }^{3}$, Philip Zachariah ${ }^{4}$,
} David H. Chong ${ }^{5}$, Anne-Catrin Uhlemann ${ }^{3}$, Julian A. Abrams ${ }^{6}$, Harris H. Wang ${ }^{1}$ and Daniel E. Freedberg ${ }^{6 *}$ (D)

\begin{abstract}
Background: The need for early antibiotics in the intensive care unit (ICU) is often balanced against the goal of antibiotic stewardship. Long-course antibiotics increase the burden of antimicrobial resistance within colonizing gut bacteria, but the dynamics of this process are not fully understood. We sought to determine how short-course antibiotics affect the antimicrobial resistance phenotype and genotype of colonizing gut bacteria in the ICU by performing a prospective cohort study with assessments of resistance at ICU admission and exactly $72 \mathrm{~h}$ later.

Methods: Deep rectal swabs were performed on 48 adults at the time of ICU admission and exactly $72 \mathrm{~h}$ later, including patients who did and did not receive antibiotics. To determine resistance phenotype, rectal swabs were cultured for methicillin-resistant Staphylococcus aureus (MRSA) and vancomycin-resistant Enterococcus (VRE). In addition, Gram-negative bacterial isolates were cultured against relevant antibiotics. To determine resistance genotype, quantitative PCR (qPCR) was performed from rectal swabs for 87 established resistance genes. Withinindividual changes in antimicrobial resistance were calculated based on culture and $\mathrm{QPCR}$ results and correlated with exposure to relevant antibiotics (e.g., did $\beta$-lactam antibiotic exposure associate with a detectable change in $\beta$ lactam resistance over this 72-h period?).
\end{abstract}

Results: Of 48 ICU patients, 41 (85\%) received antibiotics. Overall, there was no increase in the antimicrobial resistance profile of colonizing gut bacteria during the 72-h study period. There was also no increase in antimicrobial resistance after stratification by receipt of antibiotics (i.e., no detectable increase in $\beta$-lactam, vancomycin, or macrolide resistance regardless of whether patients received those same antibiotics). This was true for both culture and PCR. Antimicrobial resistance pattern at ICU admission strongly predicted resistance pattern after $72 \mathrm{~h}$.

Conclusions: Short-course ICU antibiotics made little detectable difference in the antimicrobial resistance pattern of colonizing gut bacteria over $72 \mathrm{~h}$ in the ICU. This provides an improved understanding of the dynamics of antimicrobial resistance in the ICU and some reassurance that short-course antibiotics may not adversely impact the stewardship goal of reducing antimicrobial resistance.

Keywords: Antimicrobial resistance, Antibiotics, Sepsis, Colonization, Healthcare-associated infection

\footnotetext{
* Correspondence: cm3297@cumc.columbia.edu;

def2004@cumc.columbia.edu

'Department of Systems Biology, Columbia University Irving Medical Center,

3960 Broadway, New York, NY 10032, USA

${ }^{6}$ Division of Digestive and Liver Diseases, Columbia University Irving Medical

Center, 630 West 168th Street, P\&S 3-401, New York, NY 10032, USA

Full list of author information is available at the end of the article
}

C C The Author(s). 2020 Open Access This article is licensed under a Creative Commons Attribution 4.0 International License, which permits use, sharing, adaptation, distribution and reproduction in any medium or format, as long as you give appropriate credit to the original author(s) and the source, provide a link to the Creative Commons licence, and indicate if changes were made. The images or other third party material in this article are included in the article's Creative Commons licence, unless indicated otherwise in a credit line to the material. If material is not included in the article's Creative Commons licence and your intended use is not permitted by statutory regulation or exceeds the permitted use, you will need to obtain permission directly from the copyright holder. To view a copy of this licence, visit http://creativecommons.org/licenses/by/4.0/ The Creative Commons Public Domain Dedication waiver (http://creativecommons.org/publicdomain/zero/1.0/) applies to the data made available in this article, unless otherwise stated in a credit line to the data. 


\section{Introduction}

Empiric antibiotics are the main pillar of sepsis treatment in the intensive care unit (ICU). There is a $10-42 \%$ absolute increase in sepsis mortality when initial empiric antibiotics fail to appropriately treat infecting organisms [1-3]. Clinical guidelines recommend that broadspectrum, empiric antibiotics be initiated as part of a treatment bundle within $1 \mathrm{~h}$ of presentation with sepsis [4], and studies suggest that outcomes may improve when antibiotics are given as quickly as possible [5].

Balanced against the imperative for early, broadspectrum antibiotics is the mandate for antibiotic stewardship. Using fewer or more narrow-spectrum antibiotics avoids drug-drug interactions, avoids antibiotic side effects, and furthers the stewardship goal of minimizing the emergence of antimicrobial resistance [6].

Long courses of antibiotics in the ICU are associated with increased gastrointestinal antimicrobial resistance [7]. The impact of short-course antibiotics on antimicrobial resistance in the ICU is less certain. Large structural microbiome changes can be seen within $72 \mathrm{~h}$ after oral antibiotic intake in healthy, antibiotic-naïve volunteers [8]. Whether antimicrobial resistance can emerge so quickly following intravenous antibiotics in the ICU is not known.

This study gathered rectal swabs from ICU patients immediately at the time of ICU admission and $72 \mathrm{~h}$ later, and compared changes in gastrointestinal antimicrobial resistance in those who did or did not receive antibiotics among different classes. The goal of the study was to determine if short-term antibiotics adversely impact gastrointestinal antimicrobial resistance in the ICU.

\section{Methods}

\section{Population}

A random subset of 48 patients was selected from a previously described prospective cohort parent study [9, 10]. Adults $\geq 18$ years old were eligible for the parent study if they were emergently admitted to the ICU from 2017 to 2019 at our institution, and if rectal swabs could be obtained within $4 \mathrm{~h}$ of ICU admission. The parent study gathered rectal swabs on patients at ICU admission and $72 \mathrm{~h}$ later $( \pm 4 \mathrm{~h})$. This 72 -h timeframe represents a common minimum period after which antibiotic discontinuation might be considered [4]. For this study, 48 patients were selected using a random-picking algorithm from 179 patients within the parent study who had available sequenced rectal swabs from both ICU admission and $72 \mathrm{~h}$ later. All patients in the study had single rooms (no roommates) and gown and glove contact precautions were used for the duration of the study for patients with known MRSA, VRE, C. difficile, or extended-spectrum $\beta$-lactamase (ESBL) Gram-negative colonization. Informed consent was obtained from all subjects or from appropriate surrogates when subjects lacked capacity. The study was approved by the institutional review board of Columbia University.

\section{Study assessments}

At each study assessment (ICU admission and $72 \mathrm{~h}$ later), samples were taken and clinical information was gathered. Two duplicate deep rectal flocked nylon swabs [11] were collected with the patient in the lateral decubitus position, with fecal staining of swabs used to verify adequate sampling. Demographic information, laboratory data, and data related to interventions performed in the ICU between study visits were extracted from the electronic medical record. For laboratory data, test results were used from the first venous blood draw in the ICU (corresponding to the first study assessment) and from a venous blood draw either at or immediately preceding the $72 \mathrm{~h}$ mark (corresponding to the second study assessment). ICU interventions were recorded including antibiotics, proton pump inhibitors, mechanical ventilation, hemodialysis, and enteral feeding. Clinical and laboratory data were used to estimate acute severity of illness according to the Sequential Organ Failure Assessment (SOFA) score as recommended by Sepsis-3 [12].

\section{Receipt of antibiotics}

The study enrolled patients who did and did not receive antibiotics during the initial $72 \mathrm{~h}$ in the ICU. Use of antibiotics, and which antibiotics were used, was determined by treating ICU teams based on clinical need, without reference to the study. Receipt of antibiotics was classified categorically, without respect to the number of doses or route of administration, based on whether antibiotics were received in the ICU between the initial admission rectal swab and the $72-\mathrm{h}$ rectal swab. For this study, antibiotics were considered broad-spectrum if they fell within the following class categories: $\beta$-lactam/ $\beta$-lactamase inhibitor combination antibiotics, carbapenems, cephalosporins, fluoroquinolones, and lincosamides. This definition covers 5 of the 7 most commonly prescribed classes of antibiotics in US hospitals [13]. The term $\beta$-lactams has been used to describe ampicillin, $\beta$-lactam $/ \beta$-lactamase combination antibiotics, carbapenems, and cephalosporins.

\section{Resistance phenotype}

Resistance phenotype was determined using selective and non-selective cultures. Rectal swabs were inoculated into soy broth with $20 \%$ glycerol media at the bedside. After gentle mixing, these swabs were plated on 3 media: (1) selective chromogenic media for VRE including $E$. faecalis or E. faecium, (2) selective chromogenic media for MRSA, and (3) MacConkey II agar for Gramnegative bacteria. All plates were incubated aerobically 
at $33-37^{\circ} \mathrm{C}$ and assessed after $>24 \mathrm{~h}$. VRE and MRSA were classified as present versus absent according to the manufacturer's instructions. Resistance phenotype for Gram-negative isolates was determined using the VITEK 2 system and AST-N010/020 cards with confirmatory testing as needed. Routine Clinical and Laboratory Standards Institute (CLSI) cut-offs were used for nonsusceptibility [14].

\section{Resistance genotype}

Resistance genotype was determined using a quantitative PCR kit that assesses 87 common antibiotic resistance genes (complete list of genes in Supplemental Table 1, Qiagen Cat. No. 330261) [15]. To do this, DNA was extracted from the duplicate rectal swab and $250 \mathrm{ng}$ of template meta-genomic DNA was added to each reaction on a 96-well RT-PCR plate and run according to the manufacturer's protocol. Controls were used to detect the presence of bacterial DNA, PCR inhibitors, and background. Adequate reactions were determined by cycle thresholds $\left(C_{\mathrm{T}}\right)$ values of $<29$ for the pan-bacterial reference genes $16 S$ rRNA, gyrA, recA, and rpoB and positive PCR control $C_{\mathrm{T}}$ values of $<24$ [16]. Genotype was classified both as a continuous variable based on $C_{\mathrm{T}}$ value and also, per assay recommendations, as a categorical variable with $C_{\mathrm{T}}$ values of $\leq 34$ considered positive for the presence of a given gene.

\section{Statistical approach}

Summary data was compared using chi-squared tests or Fisher's test when cell counts were $<5$. For continuous summary data, $t$ tests or rank-sum tests were used when the data was not normal in distribution. Chi-squared or Fisher's tests were used to compare resistance-related outcomes that were classified categorically; patients who already showed resistance at ICU admission were excluded from such testing, because they did not have the possibility of developing new colonization. The final sample size of 48 patients gave $80 \%$ power to detect a difference in paired means representing antimicrobial resistance genotype of 0.41 standard deviations, with resistance genotype classified as a continuous variable based on $C_{\mathrm{T}}$ value. All testing was done two-sided at an alpha 0.05 level of significance using $R$.

\section{Results}

\section{Population}

A total of 48 critically ill patients were included in the study and swabbed at the time of ICU admission and $72 \mathrm{~h}$ later (Table 1). This 72 -h window was selected because antibiotic discontinuation in the ICU is often first considered after $72 \mathrm{~h}$ of antibiotic treatment. Median sequential organ failure (SOFA) score was 16 (IQR, 10-18) at ICU admission and 17 (IQR, 15-19) after $72 \mathrm{~h}$ (Supplemental Table 2). Raw data
Table 1 Baseline characteristics of the patients in the study, treatments received in the ICU, and clinical outcomes within 30 days

\begin{tabular}{ll}
\hline Baseline characteristic & $\boldsymbol{N}(\%), \boldsymbol{N}$ total $=48$ \\
\hline Age (median years, IQR) & $64(52-74)$ \\
Female & $21(44 \%)$ \\
Admitted to ICU from hospital floor & $12(25 \%)$ \\
Baseline immunosuppression & $18(38 \%)$ \\
Primary reason for ICU admission, organized by organ system \\
Cardiovascular/shock & $14(29 \%)$ \\
Respiratory failure & $10(21 \%)$ \\
Neurological & $7(15 \%)$ \\
Gastrointestinal & $6(13 \%)$ \\
Liver & $5(10 \%)$ \\
Malignancy & $3(6 \%)$ \\
Renal failure & $3(6 \%)$
\end{tabular}

Treatments received in the ICU, from the time of admission until $72 \mathrm{~h}$ later

$\begin{array}{ll}\text { Antibiotics } & \\ \text { Any antibiotics } & 41(85 \%) \\ \text { Broad-spectrum antibiotics } & 39(81 \%) \\ \text { Non-antibiotic interventions } & \\ \text { Enteral feeding } & 36(75 \%) \\ \text { Opioids } & 35(73 \%) \\ \text { Mechanical ventilation } & 26(54 \%) \\ \text { Proton pump inhibitors } & 22(46 \%) \\ \text { Hemodialysis } & 6(13 \%)\end{array}$

Clinical outcomes within 30 days of ICU admission*

$\begin{array}{ll}\text { Culture-proven infections } & 19(40 \%) \\ \text { MDR infections } & 14(29 \%) \\ \text { Death } & 11(23 \%)\end{array}$

Immunosuppression was defined as a history of solid organ transplant or as a receipt of ablative chemotherapy, steroids at the equivalent of $\geq 5 \mathrm{mg} /$ day prednisone, antimetabolites, anti-TNFa agents, calcineurin inhibitors, or mycophenolate. Broad-spectrum antibiotics were $\beta$-lactam/ $\beta$-lactamase inhibitor combination antibiotics, cephalosporins, fluoroquinolones, lincosamides (clindamycin), and monobactams (e.g., meropenem) *See reference [17] for operationalization of culture-proven infections; MDR infections were the subset of culture-proven infections caused by MRSA, VRE, and Gram-negative bacteria with non-susceptibility to 3rd-generation cephalosporins

for the study is given in Data Supplement 1 (phenotype) and Data Supplement 2 (genotype).

\section{Receipt of antibiotics}

Patients were eligible for inclusion in the study if they did or did not receive antibiotics. In sum, 41/48 (85\%) of patients in the study received antibiotics and 37/48 (77\%) received broad-spectrum antibiotics, most often a 3rd-generation cephalosporin or an extended-spectrum penicillin with a $\beta$ lactamase inhibitor. Figure 1a shows the antibiotics received by class, and Fig. 1b shows pairwise combinations of 


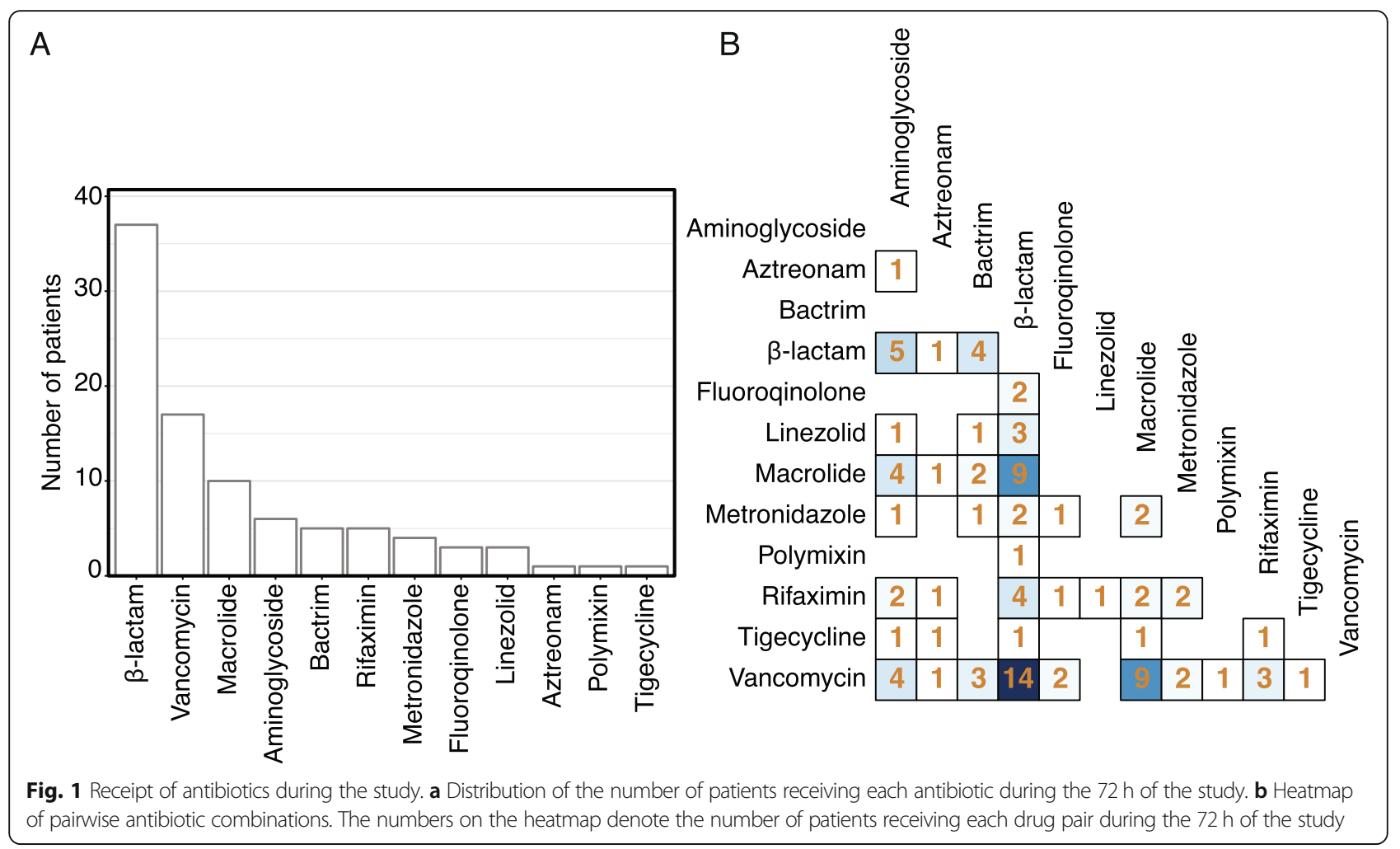

antibiotics. Almost all antibiotics were intravenous. Of 91 antibiotics dosed to the 48 patients, 93\% were given intravenously ( 1 patient received oral azithromycin, 1 received oral vancomycin, and 4 received oral rifaximin).

\section{Overall changes in antimicrobial resistance phenotype and genotype}

First, antimicrobial resistance phenotype was examined by culturing rectal swabs and performing susceptibility testing. No differences were evident comparing summary data for resistance phenotype at ICU admission versus $72 \mathrm{~h}$ later for MRSA (RR 1.4, 95\% CI 0.6-3.4; $p=0.59$ ), VRE (RR 1.4, 95\% CI 0.6-3.1; $p=0.61$ ), or Gram-negative bacteria showing $\beta$-lactam resistance (RR 1.4, CI 0.8-2.4; $p=0.27$ (Fig. 2)). Summing all antimicrobial resistance phenotype categories, there were no differences in rates of antimicrobial resistance for Gram-negative bacteria comparing ICU

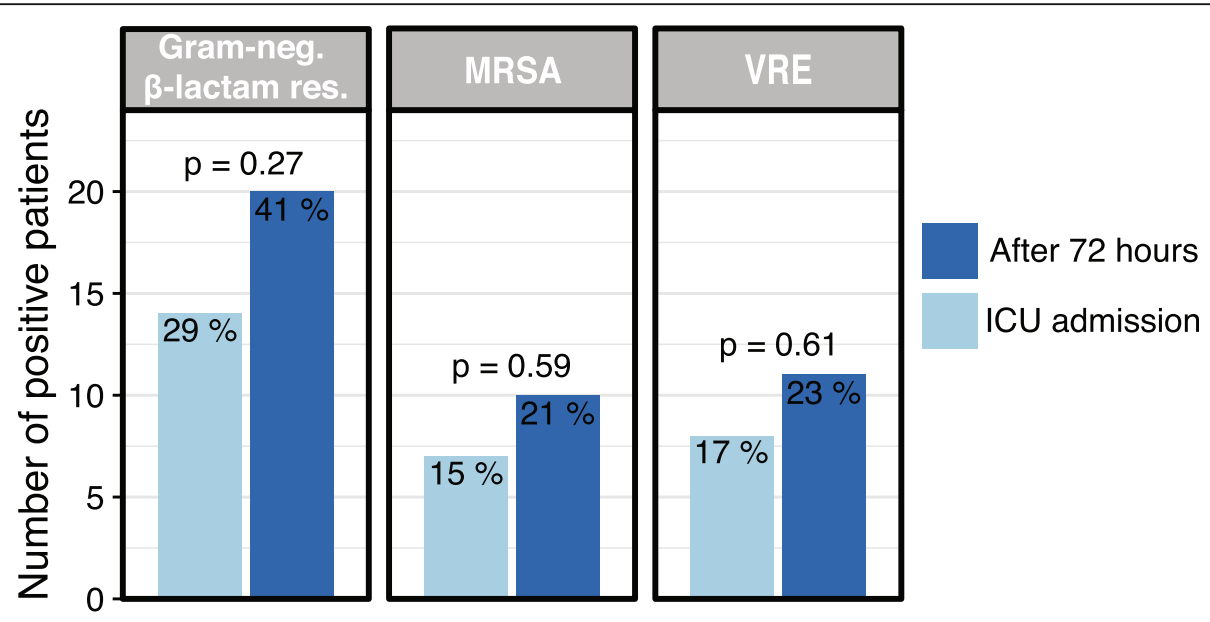

Fig. 2 Incidence of antimicrobial resistance phenotype at ICU admission and $72 \mathrm{~h}$ later, based on culture for $\beta$-lactam resistance in Gram-negative bacteria, MRSA, and VRE. There was no significant increase in resistance after $72 \mathrm{~h}$ although there were trends in that direction. Chi-squared or Fisher's $p$ values are shown 
admission (non-susceptibility for $88 / 960$ antibiotics tested, 9.1\%) versus $72 \mathrm{~h}$ later (non-susceptibility for 107/960 antibiotics tested, 11.1\%) (chi-squared $p=0.17$ ).

Next, antimicrobial resistance genotype was examined by performing qPCR across 87 common antibiotic resistance genes from the rectal swabs. No differences were evident comparing summary genotype data from ICU admission versus $72 \mathrm{~h}$ later for genes conferring resistance to $\beta$-lactams (chi-squared $p=0.27$ ), vancomycin $(p=1.0)$, macrolides $(p=0.93)$, or fluoroquinolones $(p=$ 0.74) (Supplemental Fig. 1). Summing all resistance genes, there were no differences in rates of antimicrobial resistance comparing ICU admission (positive qPCR for 392 of 4176 genes, 9\%) versus $72 \mathrm{~h}$ later (positive qPCR for 421 of 4176 genes, 10\%) (chi-squared $p=0.30$ ).

\section{Effect of antibiotics on antimicrobial resistance phenotype}

For patients that did not carry individual resistant bacteria at admission, the carriage rate after $72 \mathrm{~h}$ for those that received relevant antibiotics was compared to the carriage rate for those that did not receive relevant antibiotics (e.g., comparing $\beta$-lactam non-susceptibility in culture based on receipt of $\beta$-lactam antibiotics). Antibiotics had no significant association with resistance phenotype (Fig. 3). Emergence of Gram-negative bacteria showing resistance to at least one $\beta$-lactam antibiotic after $72 \mathrm{~h}$ was seen in $8 / 24$ (33\%) of patients who received $\beta$-lactam antibiotics and in $2 / 10(20 \%)$ of patients who did not (RR 1.7, 95\% CI 0.43-6.51; Fisher's $p=$ $0.68)$. VRE was present in $1 / 13(8 \%)$ patients who received vancomycin and in $2 / 27(7 \%)$ of patients who did not (RR 1.0, 95\% CI 0.10-10.4; $p=1.0$ ). MRSA was present in $5 / 31(16 \%)$ patients who received $\beta$-lactams and in $0 / 10(0 \%)$ of patients who did not (RR unable; $p=0.31$ ). No other clinical interventions (enteral feeding, opioids, mechanical ventilation, and proton pump inhibitors) associated with detectable differences in resistance phenotype.

\section{Effect of antibiotics on antimicrobial resistance genotype} Change in antimicrobial resistance gene abundance was tested after stratifying by receipt of antibiotic class (Fig. 4). This was first done with a change in genotype classified as a continuous variable based on withinindividual change in $C_{\mathrm{T}}$ values (ICU admission $C_{\mathrm{T}}$ minus $72-\mathrm{h} C_{\mathrm{T}}$ ). There was no association between the changes within relevant resistance genes after $72 \mathrm{~h}$ and receipt of any of the 3 most common antibiotic categories ( $\beta$-lactams, vancomycin, or macrolides). There was also no overall difference in the within-individual change in $C_{\mathrm{T}}$ values comparing combined antibiotic gene categories ( $t$ test $p=0.49$ for $\beta$-lactams, $p=0.28$ for vancomycin, and $p=0.19$ for macrolides) (Fig. 4). This analysis was then repeated classifying within-individual change in genotype categorically (i.e., present versus absent). Again, there was no association between receipt of antibiotics and changes within relevant antibiotic resistance genotypes. Last, other ICU interventions were examined. Opioids were associated with modestly reduced withinindividual risk of an increase in combined genotype (RR $0.79,95 \%$ CI $0.69-0.91 ; p<0.01)$. No other clinical

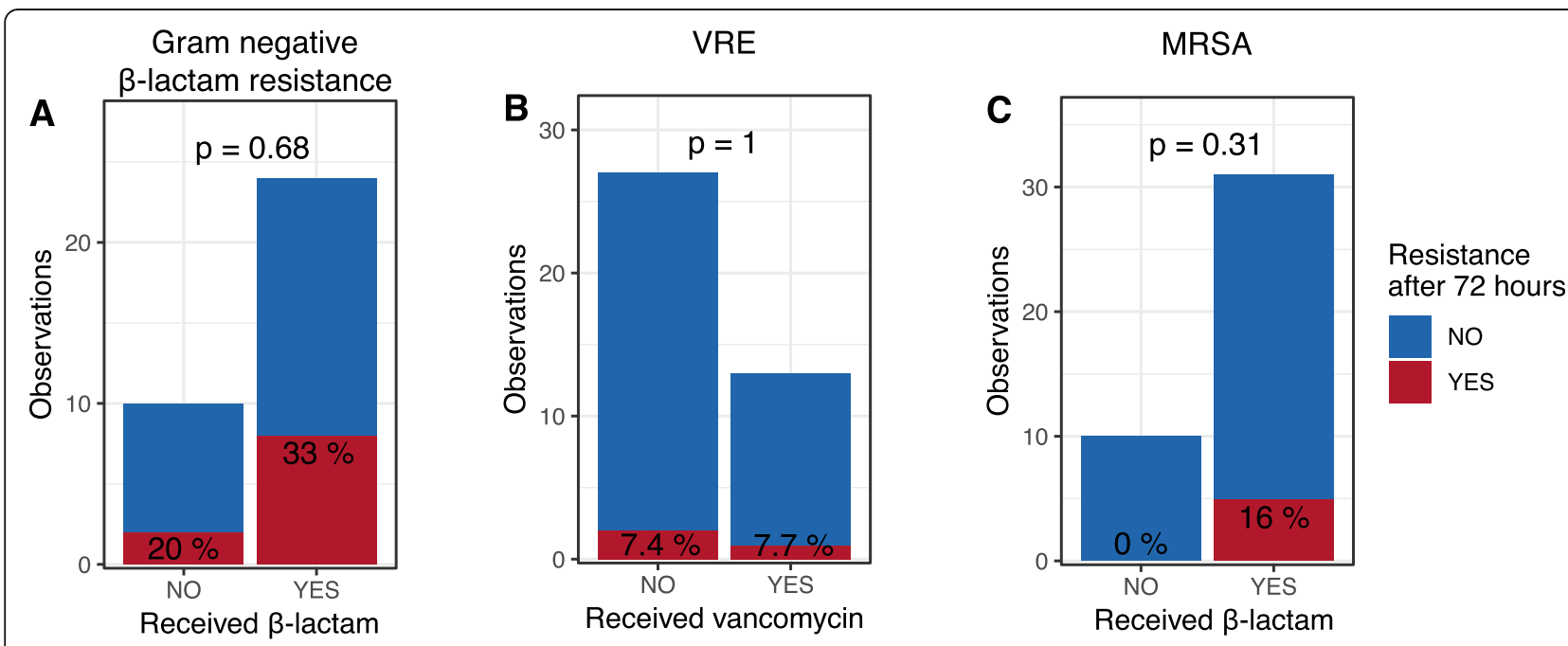

Fig. 3 Change in antimicrobial resistance phenotype stratified by receipt of antibiotics. The vertical axis for each panel shows the number of patients who did (red) or did not (blue) test positive for resistance within an antibiotic class category. This data is then stratified on the horizontal axis by whether antibiotics within that same category were received (e.g., $\beta$-lactam resistance and receipt of $\beta$-lactam antibiotics). The panels are for a Gram-negative bacteria with $\beta$-lactam resistance, b vancomycin-resistant Enterococcus (VRE), and c methicillin-resistant Staphylococcus aureus (MRSA). In all panels, data is shown based on testing done after $72 \mathrm{~h}$ in the ICU for individuals that tested negative at admission. $p$ values are for Fisher's test, comparing resistance after $72 \mathrm{~h}$ based on receipt of antibiotics within the relevant category 


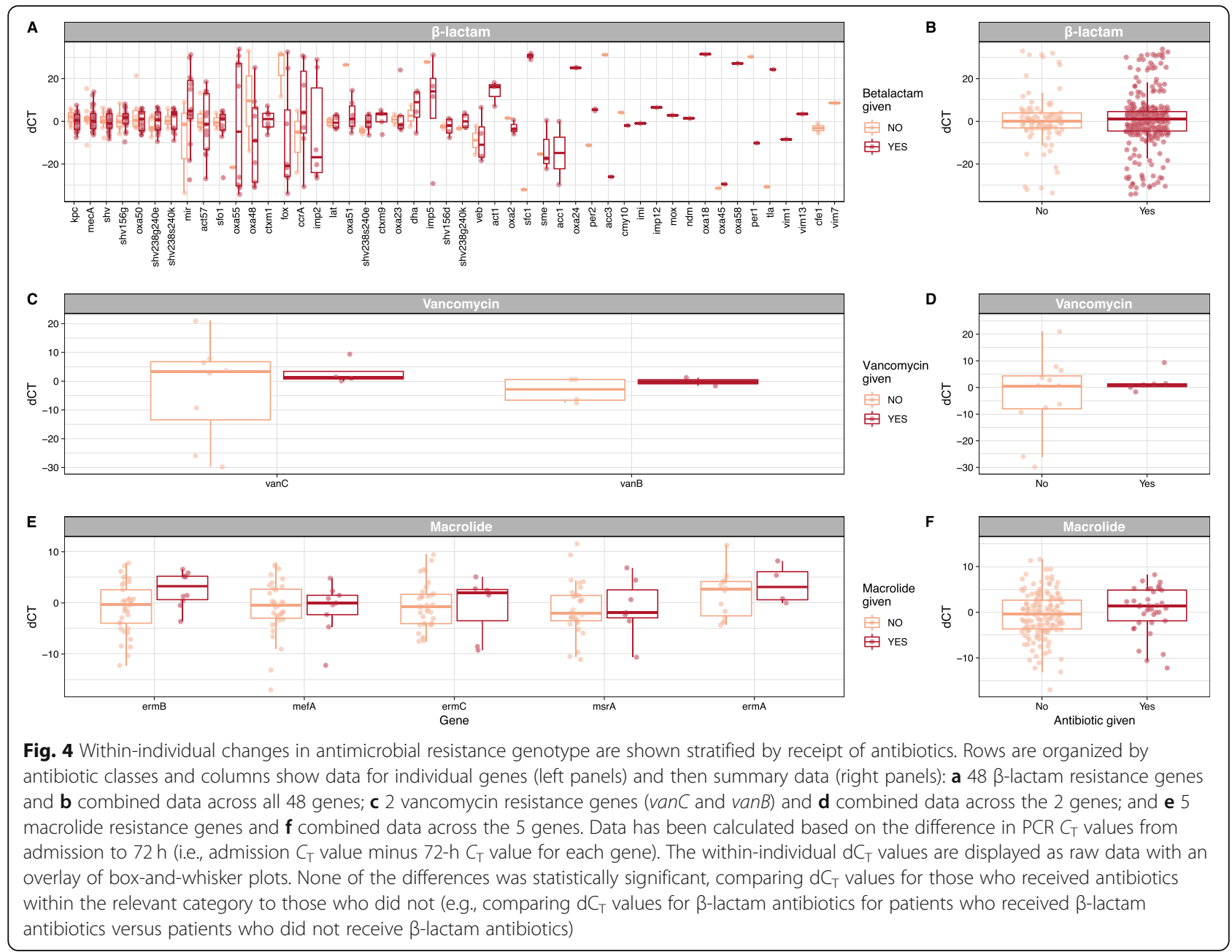

interventions associated with detectable differences in resistance genotype.

\section{ICU admission antimicrobial resistance pattern as a predictor of resistance phenotype and genotype after 72 h}

Last, the ICU admission antimicrobial resistance pattern was examined as a predictor of resistance after $72 \mathrm{~h}$ for both phenotype and genotype. For 7 of the 9 antimicrobial resistance categories tested, presence of the resistant phenotype (i.e., non-susceptibility in culture) at the time of ICU admission was significantly associated with nonsusceptibility $72 \mathrm{~h}$ later (Fig. 5a). For 14 of the 26 genes tested, presence of the resistance genotype (i.e., positive qPCR) at the time of ICU admission was significantly associated with positive qPCR $72 \mathrm{~h}$ later (Fig. 5b).

\section{Discussion}

In this study of 48 critically ill patients, there was no association between receipt of short-course antibiotics and change in antimicrobial resistance phenotype or genotype during the $72 \mathrm{~h}$ following ICU admission. Initial patient-level ICU antimicrobial resistance pattern was the best predictor of antimicrobial resistance after $72 \mathrm{~h}$, and significant interim changes were rare. Opioids, which have traditionally been associated with poor ICU outcomes, were associated with modestly reduced overall resistance in antimicrobial genotype.

This study addressed the question of short-term resistance dynamics within the gut microbiome of ICU patients. Clinically, the imperative for early broadspectrum antibiotics in the ICU is balanced against the desire for antibiotic stewardship. Decisions regarding use of antibiotics for sepsis are usually made before diagnostic microbiology results are available $[18,19]$. Can intensivists reasonably give and continue empiric broadspectrum antibiotics for $72 \mathrm{~h}$ without excessive concern that they are promoting antimicrobial resistance? Our results are reassuring but must be interpreted with caution. Prior studies clearly establish that antimicrobial resistance arises within colonizing gut bacteria during long-term antibiotic treatment in the ICU. The question 

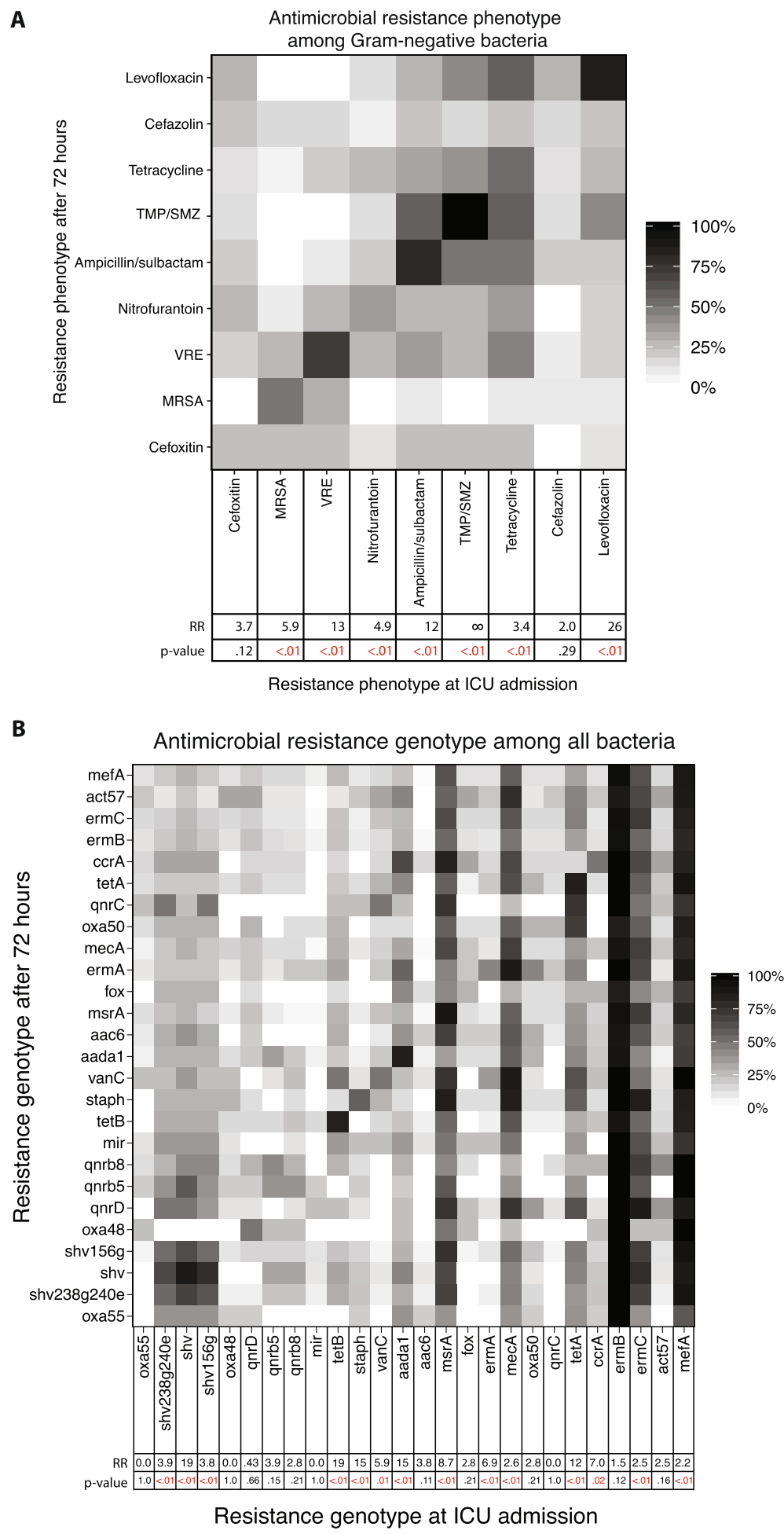

Fig. 5 Relationship between individuals' resistance pattern at ICU admission compared to $72 \mathrm{~h}$ later, for antimicrobial resistance phenotype and genotype. a Heatmap depicting the percentage of patients with resistant isolates at $72 \mathrm{~h}$ that also had resistant isolates at admission. $\mathbf{b}$ Heatmap depicting the percentage of patients with resistance genes at $72 \mathrm{~h}$ that also had resistance genes at admission. For both heatmaps, horizontal axes are resistance at admission and vertical axes are resistance after $72 \mathrm{~h}$. Bottom rows show (1) relative risk (RR) of testing positive for a resistance category at $72 \mathrm{~h}$ for those that were resistant to the same category at admission versus those who tested negative on admission and (2) $p$ values for the same comparison. In panel $\mathbf{b}$, the cases of $\mathrm{RR}=0$ reflect that no sample-pairs were positive on both admission and $72 \mathrm{~h}$ later 
is not if resistance develops but when. The 72-h treatment window in this study parallels the 3-day interval after which antibiotic discontinuation is sometimes considered in the ICU $[4,20]$. The results suggest that $72 \mathrm{~h}$ is not long enough for the development of new gastrointestinal antimicrobial resistance within a given individual. Longer antibiotic treatment window periods would almost certainly have led to different study results.

These findings regarding the dynamics of resistance contrast sharply with in vitro studies. When bacterial isolates are exposed to selective pressure in culture, mutations that confer antimicrobial resistance are rapidly selected $[21,22]$. Compared to in vitro systems, the gut microbiome of ICU patients has many competing selection pressures. This dense network of interactions may delay selection for antimicrobial resistance genes [23]. In ICU patients, collapse of the pre-existing gut microbiome and emergence of a pathobiome enriched in resistance may require 11-14 days of antibiotic treatment $[24,25]$. Other studies suggest that resistance does emerge, but does so slowly. In allogeneic stem cell transplant patients, emergence of new resistance within multiple VRE clones was seen after 7 days of selective antibiotics, with most new resistance observed after 3 weeks or more [26]. In an infant treated with multiple antibiotics, 2 months were required before antimicrobial resistance emerged within specific bacterial lineages [27, 28]. In a similar study, novel plasmid-mediated ampicillin resistance was acquired after 16-32 days in the absence of antibiotic treatment [29]. The implication is that resistance within complex human systems such as the gut arises over weeks instead of days [7].

Multiple factors probably contributed to the relatively modest changes observed in antimicrobial resistance. The antibiotics received were $93 \%$ intravenous. Intravenous antibiotics do penetrate into the gut [30], but luminal concentrations and pharmacodynamics may matter [31]. Another possibility is that patients were already too enriched in antimicrobial resistance at the time of ICU admission because of past antibiotic exposures to detect a meaningful change in resistance over $72 \mathrm{~h}$. Prior studies support such a conclusion. Willmann et al. found surprisingly little gains in fluoroquinolone resistance during prophylaxis of neutropenic patients, perhaps because of past exposures [32].

This study has limitations. It did not seek to correlate antimicrobial resistance with specific bacterial lineages and cannot state whether "new" antimicrobial resistance was acquired from the environment, from horizontal gene transfer, or vertically within bacterial lineages. Such correlations are technically challenging [33]. Rather, a standard clinical culture-based approach was used to identify resistance within the primarily Gram-negative bacteria that cause most serious ICU infections [34].
Then quantitative PCR was added to determine resistance genotype. Alternative methodologies could have been used for genotyping [35], but qPCR was selected for ease of performance and high sensitivity [36]. The ICUs involved were high-acuity regional referral centers, and results may not generalize perfectly to other ICUs. Last, the study was relatively small. While there were within-individual increases in antibiotic resistance based on culture (see Fig. 2), the study was not powered to detect weak relationships between antibiotics and antimicrobial resistance, especially for certain antibiotic class categories where few patients were unexposed. Given the large historical benefits attributed to antibiotics, a modest effect on antimicrobial resistance is unlikely to significantly alter the clinical risk-benefit calculation.

\section{Conclusions}

In sum, no clear relationship could be detected between receipt of antibiotics and antimicrobial resistance within colonizing gut bacteria during the initial $72 \mathrm{~h}$ in the ICU. This was the case for resistance phenotype based on culture and resistance genotype based on qPCR. Antimicrobial resistance was relatively stable between ICU admission and the $72 \mathrm{~h}$ mark. This result may provide some reassurance that short-course antibiotics given at ICU admission do not necessarily have an adverse effect on individuals' antimicrobial resistance.

\section{Supplementary information}

Supplementary information accompanies this paper at https://doi.org/10. 1186/s13054-020-03061-8.

Additional file 1: Table S1. Antibiotic resistance genes tested with qPCR, organized by category.

Additional file 2: Table S2. Sequential Organ Failure Assessment (SOFA) characteristics and scores, calculated at the time of ICU admission and 72 hours later.

Additional file 3: Figure S1. Incidence of antimicrobial resistance genotype at ICU admission and 72 hours later based on qPCR. The resistance genes are grouped by the antibiotic class they confer resistance to. Samples were considered positive for a given gene if the $C$ value was $\leq 34$, There was no significant increase in resistance genotype after 72 hours. Chi-squared or Fisher's $p$-values are shown.

Additional file 4.

Additional file 5 .

\section{Abbreviations}

ICU: Intensive care unit; IQR: Interquartile range; MDR: Multidrug resistant; MRSA: Methicillin-resistant Staphylococcus aureus; PCR: Polymerase chain reaction; VRE: Vancomycin-resistant Enterococcus

\section{Acknowledgements}

Not applicable.

Authors' contributions

DEF, CM, RS, and JAA contributed to the design and conception of the study; EC, JW, SS, DHC, and ACU contributed to data acquisition; and DEF and $C M$ conducted statistical analyses. DEF and CM drafted the manuscript 
and all authors have interpreted the data and provided critical revisions. All authors have read and approved the final manuscript.

\section{Funding}

CM was supported in part by the Carlsberg Foundation; RUS was supported in part by a Fannie and John Hertz Foundation Fellowship and by a NSF Graduate Research Fellowship (DGE-1644869); ACU was supported in part by NIAID R01 Al116939; JAA was supported in part by NCI U54 CA163004; HHW was supported in part by NIAID R01Al132403, NIDDK R01DK118044, and the Burroughs Welcome Fund PATH (1016691); and DEF was supported in part by NIDDK K23 DK111847. ACU has received unrelated funding from Merck, GSK, and Allergan. None of the funding organizations had any direct involvement in the study.

\section{Availability of data and materials}

Complete raw data for the study has been made available as an online supplement at https://doi.org/10.1186/s13054-020-03061-8.

\section{Ethics approval and consent to participate}

This study was approved by the institutional review board of Columbia University with participation from subjects or from surrogates when subjects lacked capacity.

\section{Consent for publication}

Not applicable.

\section{Competing interests}

The authors declare that they have no competing interests. H.H.W. is a scientific advisor to SNIPR Biome.

\section{Author details}

'Department of Systems Biology, Columbia University Irving Medical Center, 3960 Broadway, New York, NY 10032, USA. ²Department of Medicine, Columbia University Irving Medical Center, New York, USA. ${ }^{3}$ Division of Infectious Diseases, Columbia University Irving Medical Center, New York, USA. ${ }^{4}$ Division of Pediatric Infectious Diseases, Columbia University Irving Medical Center, New York, USA. ${ }^{5}$ Division of Pulmonary, Allergy, and Critical Care Medicine, Columbia University Irving Medical Center, New York, USA. ${ }^{6}$ Division of Digestive and Liver Diseases, Columbia University Irving Medical Center, 630 West 168th Street, P\&S 3-401, New York, NY 10032, USA.

\section{Received: 5 February 2020 Accepted: 4 June 2020}

\section{Published online: 09 July 2020}

\section{References}

1. Paul M, Shani V, Muchtar E, Kariv G, Robenshtok E, Leibovici L. Systematic review and meta-analysis of the efficacy of appropriate empiric antibiotic therapy for sepsis. Antimicrob Agents Chemother. 2010;54(11):4851-63.

2. Kumar A, Ellis P, Arabi Y, Roberts D, Light B, Parrillo JE, Dodek P, Wood G, Kumar A, Simon D, et al. Initiation of inappropriate antimicrobial therapy results in a fivefold reduction of survival in human septic shock. Chest. 2009; 136(5):1237-48.

3. Ferrer R, Artigas A, Suarez D, Palencia E, Levy MM, Arenzana A, Perez XL, Sirvent JM, Edusepsis Study G. Effectiveness of treatments for severe sepsis: a prospective, multicenter, observational study. Am J Respir Crit Care Med. 2009;180(9):861-6.

4. Rhodes A, Evans LE, Alhazzani W, Levy MM, Antonelli M, Ferrer R, Kumar A Sevransky JE, Sprung CL, Nunnally ME, et al. Surviving Sepsis Campaign: international guidelines for management of sepsis and septic shock: 2016. Crit Care Med. 2017:45(3):486-552.

5. Seymour CW, Gesten F, Prescott HC, Friedrich ME, Iwashyna TJ, Phillips GS, Lemeshow S, Osborn T, Terry KM, Levy MM. Time to treatment and mortality during mandated emergency care for sepsis. N Engl J Med. 2017; 376(23):2235-44

6. Callahan BJ, McMurdie PJ, Rosen MJ, Han AW, Johnson AJ, Holmes SP. DADA2: high-resolution sample inference from Illumina amplicon data. Nat Methods. 2016;13(7):581-3.

7. Filius PM, Gyssens IC, Kershof IM, Roovers PJ, Ott A, Vulto AG, Verbrugh HA, Endtz HP. Colonization and resistance dynamics of gram-negative bacteria in patients during and after hospitalization. Antimicrob Agents Chemother. 2005;49(7):2879-86.
8. Dethlefsen L, Relman DA. Incomplete recovery and individualized responses of the human distal gut microbiota to repeated antibiotic perturbation. Proc Natl Acad Sci U S A. 2011;108(Suppl 1):4554-61.

9. Livanos AE, Snider EJ, Whittier S, Chong DH, Wang TC, Abrams JA, Freedberg DE. Rapid gastrointestinal loss of clostridial clusters IV and XIVa in the ICU associates with an expansion of gut pathogens. PLoS One. 2018; 13(8):e0200322

10. Terry MA, Freedberg DE, Morris MC. An alternative consent process for minimal risk research in the ICU. Crit Care Med. 2017;45(9):1450-6.

11. Budding AE, Grasman ME, Eck A, Bogaards JA, Vandenbroucke-Grauls CM, van Bodegraven AA, Savelkoul PH. Rectal swabs for analysis of the intestinal microbiota. PLoS One. 2014;9(7):e101344.

12. Singer M, Deutschman CS, Seymour CW, Shankar-Hari M, Annane D, Bauer M, Bellomo R, Bernard GR, Chiche JD, Coopersmith CM, et al. The third international consensus definitions for sepsis and septic shock (Sepsis-3). JAMA. 2016;315(8):801-10.

13. Baggs J, Fridkin SK, Pollack LA, Srinivasan A, Jernigan JA. Estimating national trends in inpatient antibiotic use among US hospitals from 2006 to 2012. JAMA Intern Med. 2016;176(11):1639-48.

14. Clinical and Laboratory Standards Institute (CLSI), Performance standards for antimicrobial susceptibility testing, M100 Supplement, 2017. Accessed online at http://em100.edaptivedocs.net/GetDoc.aspx?doc=CLSI\%20M100\%2 OED30:2020\&scope $=$ user.

15. Fosbrink M, Wilt G, Chen L, Kreisworth B, Devgan V: Identification of antibiotic resistance genes in Klebsiella pneumoniae isolates and metagenomic samples using real-time PCR arrays. Sample to Insight, accessed on-line at https://www.slideshare.net/QIAGENscience/ identification-of-antibiotic-resistance-genes-in-klebsiella-pneumoniaeisolates-and-metagenomic-samples-using-realtime-pcr-arrays April 6, 2016.

16. Rocha DJ, Santos CS, Pacheco LG. Bacterial reference genes for gene expression studies by RT-qPCR: survey and analysis. Antonie Van Leeuwenhoek. 2015;108(3):685-93.

17. Freedberg DE, Salmasian H, Cohen B, Abrams JA, Larson EL. Receipt of antibiotics in hospitalized patients and risk for clostridium difficile infection in subsequent patients who occupy the same bed. JAMA Intern Med. 2016; 176(12):1801-8

18. Whiles BB, Deis AS, Simpson SQ. Increased time to initial antimicrobial administration is associated with progression to septic shock in severe sepsis patients. Crit Care Med. 2017;45(4):623-9.

19. Liu VX, Fielding-Singh V, Greene JD, Baker JM, Iwashyna TJ, Bhattacharya J, Escobar GJ. The timing of early antibiotics and hospital mortality in sepsis. Am J Respir Crit Care Med. 2017;196(7):856-63.

20. Dellit TH, Owens RC, McGowan JE Jr, Gerding DN, Weinstein RA, Burke JP, Huskins WC, Paterson DL, Fishman NO, Carpenter CF, et al. Infectious Diseases Society of America and the Society for Healthcare Epidemiology of America guidelines for developing an institutional program to enhance antimicrobial stewardship. Clin Infect Dis. 2007:44(2):159-77.

21. Good BH, McDonald MJ, Barrick JE, Lenski RE, Desai MM. The dynamics of molecular evolution over 60,000 generations. Nature. 2017;551(7678):45-50.

22. Tenaillon O, Barrick JE, Ribeck N, Deatherage DE, Blanchard JL, Dasgupta A, Wu GC, Wielgoss S, Cruveiller S, Medigue C, et al. Tempo and mode of genome evolution in a 50,000-generation experiment. Nature. 2016; 536(7615):165-70.

23. Lescat M, Launay A, Ghalayini M, Magnan M, Glodt J, Pintard C, Dion S, Denamur E, Tenaillon O. Using long-term experimental evolution to uncover the patterns and determinants of molecular evolution of an Escherichia coli natural isolate in the streptomycin-treated mouse gut. Mol Ecol. 2017:26(7):1802-17.

24. Alverdy JC, Krezalek MA. Collapse of the microbiome, emergence of the pathobiome, and the immunopathology of sepsis. Crit Care Med. 2017;45(2): 337-47.

25. Perez-Cobas $A E$, Gosalbes MJ, Friedrichs $A$, Knecht $H$, Artacho $A$ Eismann K, Otto W, Rojo D, Bargiela R, von Bergen M, et al. Gut microbiota disturbance during antibiotic therapy: a multi-omic approach. Gut. 2013;62(11):1591-601.

26. Dubin KA, Mathur D, McKenney PT, Taylor BP, Littmann ER, Peled JU, van den brink MRM, Taur Y, Pamer EG, Xavier JB: Diversification and evolution of vancomycin-resistant Enterococcus faecium during intestinal domination. Infect Immun. 2019;87(7):e00102-19.

27. Porse A, Gumpert H, Kubicek-Sutherland JZ, Karami N, Adlerberth I, Wold $\mathrm{AE}$, Andersson DI, Sommer MOA. Genome dynamics of Escherichia coli 
during antibiotic treatment: transfer, loss, and persistence of genetic elements in situ of the infant gut. Front Cell Infect Microbiol. 2017;7:126.

28. Karami N, Martner A, Enne VI, Swerkersson S, Adlerberth I, Wold AE. Transfer of an ampicillin resistance gene between two Escherichia coli strains in the bowel microbiota of an infant treated with antibiotics. J Antimicrob Chemother. 2007;60(5):1142-5.

29. Gumpert H, Kubicek-Sutherland JZ, Porse A, Karami N, Munck C, Linkevicius M, Adlerberth I, Wold AE, Andersson DI, Sommer MOA. Transfer and persistence of a multi-drug resistance plasmid in situ of the infant gut microbiota in the absence of antibiotic treatment. Front Microbiol. 2017;8: 1852.

30. Urtasun RC, Rabin HR, Partington J. Human pharmacokinetics and toxicity of high-dose metronidazole administered orally and intravenously. Surgery. 1983;93(1 Pt 2):145-8.

31. Tulstrup MV, Christensen EG, Carvalho V, Linninge C, Ahrne S, Hojberg O, Licht TR, Bahl MI. Antibiotic treatment affects intestinal permeability and gut microbial composition in wistar rats dependent on antibiotic class. PLoS One. 2015;10(12):e0144854

32. Willmann M, Vehreschild M, Biehl LM, Vogel W, Dorfel D, Hamprecht A, Seifert H, Autenrieth IB, Peter S. Distinct impact of antibiotics on the gut microbiome and resistome: a longitudinal multicenter cohort study. BMC Biol. 2019:17(1):76.

33. Ferreiro A, Crook N, Gasparrini AJ, Dantas G. Multiscale evolutionary dynamics of host-associated microbiomes. Cell. 2018;172(6):1216-27.

34. Tabah A, Koulenti D, Laupland K, Misset B, Valles J, Bruzzi de Carvalho F, Paiva JA, Cakar N, Ma X, Eggimann P, et al. Characteristics and determinants of outcome of hospital-acquired bloodstream infections in intensive care units: the EUROBACT international cohort study. Intensive Care Med. 2012; 38(12):1930-45.

35. Raymond F, Boissinot M, Ouameur AA, Deraspe M, Plante PL, Kpanou SR, Berube E, Huletsky A, Roy PH, Ouellette M, et al. Culture-enriched human gut microbiomes reveal core and accessory resistance genes. Microbiome. 2019;7(1):56.

36. Walker GT, Quan J, Higgins SG, Toraskar N, Chang W, Saeed A, Sapiro V, Pitzer K, Whitfield N, Lopansri BK, et al. Predicting antibiotic resistance in gram-negative bacilli from resistance genes. Antimicrob Agents Chemother. 2019;63(4):e02462-18.

\section{Publisher's Note}

Springer Nature remains neutral with regard to jurisdictional claims in published maps and institutional affiliations.

Ready to submit your research? Choose BMC and benefit from:

- fast, convenient online submission

- thorough peer review by experienced researchers in your field

- rapid publication on acceptance

- support for research data, including large and complex data types

- gold Open Access which fosters wider collaboration and increased citations

- maximum visibility for your research: over $100 \mathrm{M}$ website views per year

At $\mathrm{BMC}$, research is always in progress.

Learn more biomedcentral.com/submissions 